\title{
Nörofibromatozis Tip 1: Çocuk Hastalarda Klinik ve Beyin MRG Bulguları
}

\author{
NeurofibromatosisType 1: Clinical and Brain MRI Findings in \\ Pediatric Patients
}

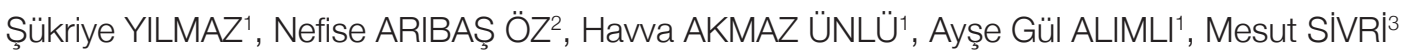

\author{
${ }^{1}$ Ankara Şehir Hastanesi, Çocuk Hastanesi, Radyoloji Kliniği, Ankara, Türkiye \\ ${ }^{2}$ Ankara Şehir Hastanesi, Çocuk Hastanesi, Çocuk Nöroloji Kliniği, Türkiye \\ ${ }^{3}$ Radyoloji uzmanı, Ankara, Türkiye
}

\section{öz}

Amaç: Nörofibromatozis tip 1, multisistem tutulumu, benign ve malign tümörlerde normal popülasyona göre artmış görülme sıklığı ile karakterize en sık görülen nörokutanöz sendromdur. Çocuklarda kanser sıklığını artırması nedeniyle teşhisi ve takibi önemlidir. Bu çalışmanın amacı nörofibromatozis tip I tanısı ile takip edilen çocuk hastalarda beyin MRG bulgularını, beynin neoplastik ve neoplastik olmayan lezyonlarını, tanı kriterlerini ve tanı anındaki bulgularını incelemektir.

Gereç ve Yöntemler: Temmuz 2010 ile Mart 2019 tarihleri arasında nörofibromatozis tip 1 tanısı almış ve en az 1 defa kontrastlı beyin MRG yapılmış toplam 183 hasta değerlendirildi. On iki hasta kardeşti. Çalışmamızda ortalama yaşı 10 (1-18 yaş) olan 82 kız ve 101 erkek, toplam 183, çocuk hasta 9 yıl deneyimli bir radyolog tarafından değerlendirildi.

Bulgular: 183 hastadan; 37 hastada beyinde hamartomatöz lezyon yoktu, 24'ünde optik gliom veya optik sinir kalınlaşması (9 bilateral, 10 sağ, 5 sol taraf), 8'inde pleksiform nörofibrom (baș veya boyun yerleşimli), 9'unda subkutan nörofibrom vardı. Ek olarak 9 hastada intrakranial araknoid kist, 6 hastada düşük dereceli glial tümör, 1 hastada medulloblastom, 1 hastada glioblastom, 1 hastada nodüler heterotopi saptandı. İki hastada düşük dereceli glial tümör şüphesi vardı ve izlemlerinde boyutları ve görünümleri stabildi. Hamartomatöz lezyonların en sık yerleşim yeri globus pallidus, dentat nükleus, mezensefalon, talamus ve ponsdu, en az yerleșim yeri ise putamendi. Ayrıca 3 hasta Noonan Sendromu ile takip ediliyordu. Bu hastaların ikisinde, hamartomatöz lezyonlara ek olarak intrakraniyal araknoid kistler gözlendi.

Sonuç: Nörofibromatozis tip 1 hastalığı mortalite ve morbidite nedeni olan, malign ve benign tümörlerin görülme sıklığında artışa yol açan tümör yatkınlık sendromlarından biridir. Gliomlar en sık görülen intrakraniyal tümörlerdir ve nörofibromlardan sonra en sık görülen ikinci tümör tipidir. Tümörlerin erken tanı ve malignitenin tedavisi için düzenli takip önemlidir. Beyin MRG Nörofibromatozis tip 1 tanılı hastalarda beyin tutulumunun tanı ve takibinde yeterli ve gerekli görüntüleme yöntemidir.

Anahtar Sözcükler: Beyin, MRG, Nörofibromatozis tip 1

\section{ABSTRACT}

Objective: Neurofibromatosis type 1 is a most common neurocutaneous syndrome characterized by multi-system involvement and an increased incidence of both benign and malignant tumors. Its diagnosis and follow-up is important because of increased cancer susceptibility in children. The aim of this study is to review the cranial MRI findings, neoplastic and non-neoplastic lesions of the brain in neurofibromatosis type I in pediatric patients.

\begin{tabular}{|c|c|c|}
\hline \multirow{6}{*}{$\begin{array}{l}\text { (1) } \\
\text { YILMAZ Ş } \\
\text { ARIBAŞ ÖZ N } \\
\text { AKMAZ ÜNLÜ H } \\
\text { ALIMLI AG } \\
\text { SIVRI M }\end{array}$} & & Çıkar Çatışması / Conflict of Interest: Tüm yazarlar adına, sorumlu yazar çıkar çatışması olmadığını belirtir. \\
\hline & \multirow{5}{*}{$\begin{array}{l}: 0000-0002-5777-6147 \\
: 0000-0002-9627-9127 \\
: 0000-0002-0291-3589 \\
: 0000-0002-4339-4236 \\
: 0000-0002-1278-3386\end{array}$} & Etik Kurul Onayı / Ethics Committee Approval: Bu çalıșmada ulusal ve uluslararası etik kurallara uyulmuștur. Çalıșma için, SBÜ. Ankara Çocuk Sağlığı \\
\hline & & ve Hastalıkları Hematoloji Onkoloji SUAM, Klinik Araştırmalar Etik Kurulu'nda 2019-162 protokol numaralı onay alınmıştır. Kayıt sırasında veliler tarafindan \\
\hline & & araştırmaya katılım için bilgilendirilmiş bir onay imzalanmıştır. \\
\hline & & 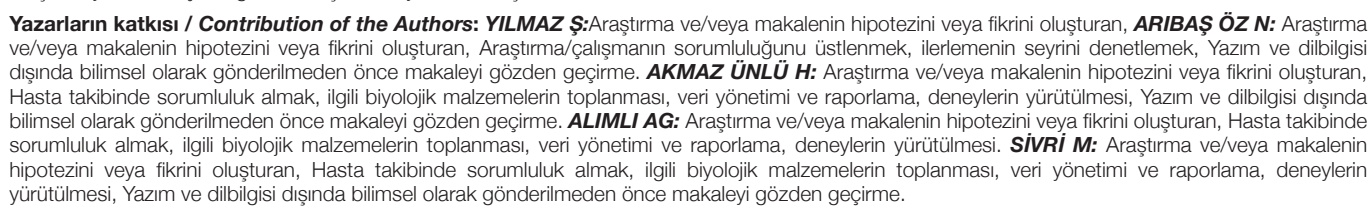 \\
\hline & & $\begin{array}{l}\text { Atıf yazım şekli / How to cite : Yllmaz Ş, Arıbaş Öz N, Akmaz Ünlü H, Alımlı AG, Sivri M. Nörofibromatozis Tip 1: Çocuk Hastalarda Klinik ve Beyin MRG } \\
\text { Bulguları. Türkiye Çocuk Hast Derg 2021;15:181-186. }\end{array}$ \\
\hline
\end{tabular}


Material and Methods: 183 patients which diagnosed with neurofibromatosis type 1 and had at least 1 MRI between July 2010 and March 2019 were evaluated. Twelve patients were siblings. Contrasted cranial MRI obtained from 82 female and 101 male patients, between ages 1-18 years (averageage 10) retrospectively scanned thereafter type and locations of lesions evaluated by a 9 years experienced radiologist.

Results: Out of 183 patients; 37 had no hamartomatous cranial lesions, 24 had optic gliomas or optic nerve thickening (9 bilaterally, 10 rightside, 5 leftside), 8 had plexiform neurofibromas (head or neck location), 9 had subcutaneous neurofibromas. Additionally 9 had intracranial arachnoid cysts, 6 low grade glial tumor, 1 medulloblastoma, 1 glioblastoma, 1 nodular heterotopia. Two patients had suspected low grade glial tumor and their size and view are stableat follow-up. The most common localization of hamartomatous lesions are the globus pallidus, dentate nucleus, mesencephalon, thalamus and pons respectively. The least common area is putamen. In addition, 3 patients are followed with Noonan Syndrome. In two of these patients, intracranial arachnoid cysts were observed in addition to hamartomatous lesions.

Conclusion: Neurofibromatosis type 1 is one of the tumor predisposition syndrome that leads to an increased incidence of malign and benign tumors, which are major cause of mortality and morbidity. Gliomas are the most common intracranial tumors and the second most common tumor type after neurofibromas. Regular follow up is important for early diagnosis and treatment of malignancy. Brain MRI is adequate and necessary imaging modality for the diagnosis and follow up of brain involment in Neurofibromatosis type 1 patients.

Key Words: Brain, MRI, Neurofibromatosis type 1

\section{GiRiș}

Nörofibromatozis Tip 1 (NF1) (von Recklinghausen hastalığı, periferal nörofibromatozis), otozomal dominant geçişli bir hastalıktır. \% 30-50 olguda sporadik olarak görülebildiği bildirilmektedir(1-3). En sıkkarşılaşılan nörokütanöz sendromdur. Tümör süpresör geni olan ve nörofibromin proteinini kodlayan 17q11.2'deki mutasyon nedeniyle oluşmaktadır ve yaklaşık 2700:1 oranında görülür (4). Bütün nörokütanöz sendromlarda olduğu gibi morbidite ve mortaliteyi etkileyen en önemli faktör malign ve benign tümor görülme sıklığında artış oluşturmasıdır. Periferik sinir kılıfı tümörleri NF1'de en sık görülen tümörlerdir. Santral sinir sistemi tümörleri periferik tümörlerden daha az sıklıkta görülmesine rağmen morbidite ve mortaliteyi büyük ölçüde etkilemesi nedeni ile önemlidir (5). İntrakranial tümörler arasında en sık \%5-15 arasında görülen optik gliomlar yer alır (6). Bunları \%1-3 oranında düşük gradeliglial tümörler izler.

NF1 tanısını düșündüren ve en sık görülen belirti vücutta izlenen sütlü kahve (cafe au lait) lekeleridir fakat bu lekeler normal popülasyonda da \%20-30 oranında görülmektedir. NF1 tanısı 1987 yılında National Institute of Health (NIH) tarafından tanımlanan tanı kriterlerinden en az ikisinin bir arada olması ile konur (7).

Manyetik rezonans görüntüleme (MRG) NF1'li hastalarda kranial bulguların değerlendirilmesinde, tanıda ve takipte, yüksek duyarlılık ve özgünlük nedeniyle tercih edilen bir yöntemdir (8). NF1 hastalarında beyin MRG' de belli lokalizasyonlarda daha sık olmak üzere T2 ve fluid attenuated inversion recovery (FLAIR) ağırlıklı imajlarda artmış fokal sinyal artışları izlenmektedir $(8,9)$. Bu hiperintens lezyonlar literatürde " NF1 bright objects (NBO)": NF1 parlak objeler, "unidentified bright objects (UBO)": bilinmeyen parlak objeler olarak isimlendirilmektedir $(9,10)$. Tariflenen bu lezyonların genel görüște hamartom olduğu kabul edilmektedir ve çoğu puberte dönemine kadar kaybolur (11). NF1 hastalarda görülen öğrenme güçlüğü, dikkat eksikliği ve hiperaktivite, bilişsel bozukluk gibi bulguların hamartomatöz lezyonlar ile ilișkili olduğu düșünülmektedir (12-14).
Bu çalışmada amacımız kliniğimizde NF1 tanısı ile takip edilen çocuk hastalarda beyin MRG bulgularını, beynin neoplastik ve nonneoplastik lezyonlarını, tanı kriterlerini ve tanı anındaki bulgularını incelemektir.

\section{GEREÇ ve YÖNTEMLER}

Çalışmada 2010-2019 tarihleri arasında klinik ve görüntüleme olarak takip edilen ve NF1 tanısı ile izlenen olgular değerlendirilmiştir. NF1 tanısı NIH tarafından tanımlanan kriterlere göre konulmuştur.

Hastaların beyin MRG incelemeleri birimimizde bulunan 1.5 Tesla GE Optima MR450w cihazı ile yapılmıştır. Kesit kalınlığı 4-5.5 mm aralığında değișmektedir. MR inceleme sagittal ve aksiyel planlarda T1 (350-700/10-20 [TR/TE]) ve T2 (3600-5500/80105 [TR/TE]) ağırlıklı sekanslardan ve FLAIR serilerle, kontrastlı aksiyel ve koronal T1 ağırlıklı görüntülerden oluşmaktadır. Intravenöz kontrast madde $0.1 \mathrm{mmol} / \mathrm{kg}$ standart dozda uygulanmıştır.

Çalışmamızda klinik ölçütlerle NF1 tanısı alan ve en az 1 kontrastlı beyin MRG incelemesi bulunan toplam 183 çocuk hasta retrospektif olarak değerlendirildi. Çalışmaya dahil edilen olgularda beyin MRG incelemesindeki lezyonların tipi ve lokalizasyonları farklı bir radyolog (9 yıl deneyimli) tarafından yeniden değerlendirilmiștir. Hastaların geriye dönük olarak tıbbi kayıtları da incelenmiş, yaş, cinsiyet, aile öyküsü, klinik bulguları kaydedilmiştir.

\section{BULGULAR}

Çalışmamıza 82 kız ve 101 erkek, toplam 183 çocuk hasta dahil edilmiştir. Hastaların yașları 1-18 yaș arasında (ortalama 10 yaş) değişmekteydi. Muayene kayıtlarına ulașılan 147 hastanın tümünde sütlü kahve lekeleri mevcuttu. Sadece 5 hastada tanı 
Tablo I: NF1 hastalarının sosyodemografik ve klinik özellikleri.

\begin{tabular}{|c|c|c|}
\hline & $\mathbf{n}$ & $\%$ \\
\hline $\begin{array}{l}\text { Cinsiyet } \\
\text { KIz } \\
\text { Erkek }\end{array}$ & $\begin{array}{c}82 \\
101\end{array}$ & $\begin{array}{l}45 \\
55\end{array}$ \\
\hline Ortalama yaş & 10 (yll) & \\
\hline Sütlü kahve lekeleri & $147 / 147$ & 100 \\
\hline Koltuk altı ve kasıkta çillenme & $63 / 147$ & 42 \\
\hline Lisch nodülü & $58 / 135$ & 43 \\
\hline Birinci derecede akrabalarda NF-1 öyküsü & $71 / 113$ & 63 \\
\hline
\end{tabular}

anında sütlü kahve lekeleri boyut ve sayı olarak tanı kriterlerini karşılamıyordu. Koltuk altı/kasıkta çillenme 63 (\%42.8) olguda mevcuttu ve bu hastaların yaş ortalaması 14.2 yıl iken çillenmesi olmayan 76 hastanın yaș ortalaması 11.8 yıldı. Lisch nodülü, göz bulgularına ulașılan 135 hastanın 58'inde (\%42.9) izlendi. Çalışmamızda 113 hastanın aile öyküsüne ulaşıldı. Bunlardan 71 (\%62.8) tanesinde ailede en az bir bireyde NF1 tanısı bulunmaktaydı. 28 olguda anne ve/veya akrabalarında, 38 olguda baba ve/veya akrabalarında, 5 olguda sadece kardeșlerinde NF1 tanısı mevcuttu (Tablo I).

Beyin MRG'de hamartomatöz (UBO) lezyonlar T1 ağırlıklı serilerde çoğunlukla beyin parankimi ile izointens, T2 ağırlıklı serilerde ise hiperintens ve sınıları belirsiz, kitle etkisi bulunmayan ve kontrastlanmayan odaklar şeklinde izlendi (Resim 1). Santral sinir sisteminde hamartomatöz lezyonu olan 145 hastanın lezyon yerleşimleri başta bilateral globus pallidus ve dentat nükleus olmak üzere mezensefalon, pons, medulla oblangata, talamus, hipokampüs, korpus kallozum ve serebellum idi ve sıklıkla çok sayıdaydı. Çoğunlukla bilateral yerleşim görülmekte olup boyut ve konfigürasyonda simetri saptanmamıştır. Bilateral yerleşimler farklı sayılmaksızın (çift taraflı simetrik tutulumlar (bilateral talamus gibi) tek lokalizasyon kabul edilerek yapılan değerlendirmede) hamartomatöz lezyon bulunan hastalardan 25 'inde (\%17) 1, 36 (\%24) hastada 2, 32 (\%22) hastada 3, 23 (\%12) hastada 4, 28 (\%19) hastada 5, 16 (\%11) hastada 6 , 3 (\%2) hastada ise 7 lokalizasyonda hamartomatöz lezyon mevcuttu. Tek bir lokalizasyonda UBO lezyonu izlenen yirmi beş hastada en sık yerleşim yeri globus pallidustu. Hamartomatöz lezyonların en sık yerleşim gösterdiği yerler dentat nükleus, mezensefalon, talamus ve pons, en az yerleşim yeri ise putamendi. Lezyon dağılımları \%23 globus pallidus, \%19 dentat nükleus, $\% 13$ mezensefalon, $\% 13$ talamus, $\% 12$ pons, \%8 serebellum, \%3 bulbus, \%3 hipokampus, \%2 korpus kallozum, ve \%1 diğer (vermis, putamen, internal kapsül ve periventriküler alan) olarak hesaplandı.

8 hastada bilateral, 15 hastada unilateral (sol 5, sağ 10) ve 1 hastada sadece optik kiazma düzeyinde olmak üzere toplam 24 (\%13) hastada optik gliom izlendi. Optik gliomu bulunan hastalardan , optik kiazma yerleșimli gliomu bulunan bir hastada beyinde UBO saptanmadı. Diğer hastaların hepsinde eşlik eden UBO mevcuttu.
Beyin MRG incelemesi sırasında kesitler dahilindeki kraniofasial alanlarda 8 hastada pleksiform nörofibrom, 9'unda subkutan nörofibrom izlendi. Bu hastalarda tanilar histopatolojik inceleme sonrası kesinleşti. Pleksiform nörofibromlar T1 ağırlıklı görüntülerde çevre doku ile izointens, T2 ağırlıklı görüntülerde hiperintens sinyal özelliğinde, üzüm salkımı şeklinde, içerisinde hipointens target benzeri görünüm izlenmiş olup heterojen kontrastlanma göstermekteydi (Resim 2). Nörofibromlar T1 ağırlıklı serilerde hafif hiperintens, T2 ağırlıklı serilerde ise hipointens, kontrast sonrası serilerde heterojen kontrastlanma gösterir şekilde izlendi.

Hastalarımızda 9 intrakranial araknoid kist, 6 düşük dereceli glial tümör, 1 medulloblastom, 1 glioblastom, 1 nodüler heterotopi vardı (Resim 3). İki hasta düşük dereceli glial tümör şüphesi ile izlenmekte olup ortalama 2 ylllik takipte boyut ve görünümleri stabildi. Sfenoid kemik displazisi hiçbir hastada gözlenmedi. NF1-Noonan fenotipi olan 3 hastanın ikisinde hamartomatöz lezyonlara ek olarak araknoid kistler izlendi.

Ayrıca 9 hastada baş ve boyun dışındaki lokalizasyonlarda cilt altı nörofibrom, 1 hastada paratestiküler rabdomyosarkom tespit edildi.

\section{TARTIŞMA}

NF1 toplumda sık karşllaşılması, ilerleyici seyir göstermesi, pek çok organ ve/veya sistemi etkilemesi ve kanser yatkınlığı yaratması nedeniyle önemli bir nörokutanöz sendromdur (15).

Sütlükahve lekeleri hastalığın en erken bulgusudur ve doğumdan itibaren görülebilir. NF1 tanılı hastaların en az \%95 inde sütlü kahve lekeleri bulunur, yașla sayı ve boyutlarında artma olur. Muayene bulgularına ulaşlan 147 hastanın tümünde sütlü kahve lekesi mevcuttu. Tanı sırasında 5 hastada sütlü kahve lekelerinin sayısı 6'dan az iken 142 hastada 6 ve üzerinde idi. Koltukaltı/ kasıkta çillenme 63 (\%42.8) olguda vardı ve bu hastaların yaş ortalaması 14.2 yı iken çillenmesi olmayan 76 hastanın yaş ortalaması 11.8 yıldı. Koltukaltı ve kasıkta çillenme ortalama 10 yaşından sonra başlar, bizim çalışmamızda ortalama daha yüksek bulundu $(16,17)$. 


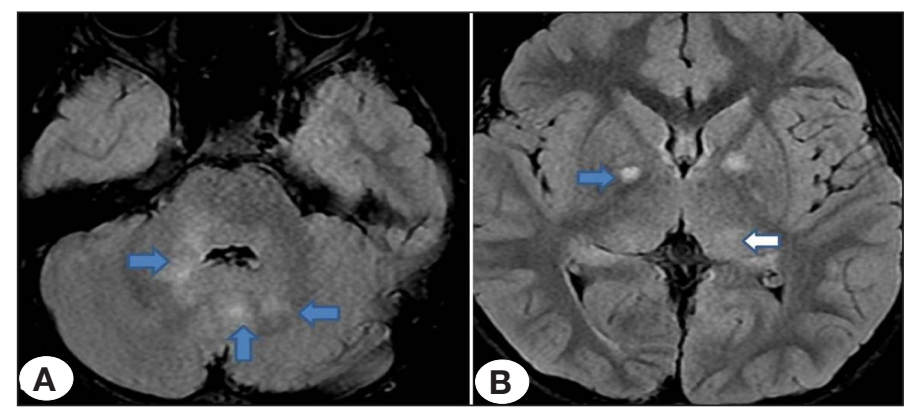

Resim 1: (A) Aksiyel FLAIR görüntüde her iki globus pallidusta (mavi ok) ve talamusta (beyaz ok), (A) 4. ventrikül komşuluğunda (oklar) hamartom ile uyumlu artmış intensiteler izleniyor.

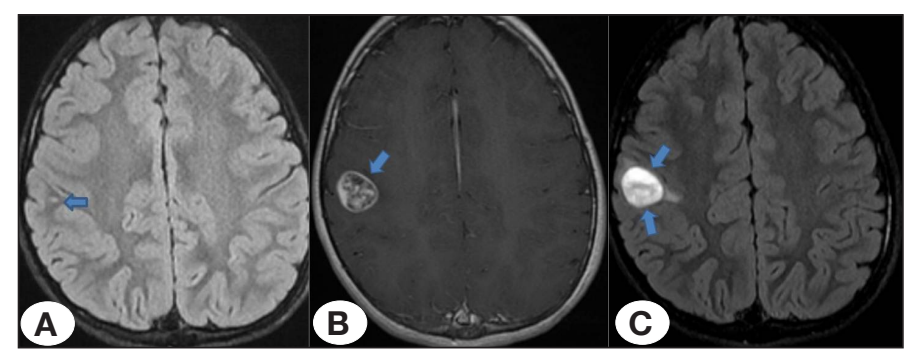

Resim 3: NF1 tanilı hastada (A) beyin MRG takibinde aksiyel FLAIR görüntüde sağ frontal subkortikal alanda yeni gelişen hiperintens nonspesifik milimetrik alan izleniyor (ok), (B) 1 ay sonra yapılan kontrol görüntülemede koronal kontrastlı T1 ağırlıklı imajda kontrastlanma gösteren (ok), (C) aksiyel T2A seride etrafında vazojenik ödem bulunan kitle izleniyor (oklar). Cerrahi sonrası patolojik tanı pilomiksoid astrositom olarak tespit edildi.

Geçmiş çalışmalarda NF1'li hastalarda lisch nodülü görülme oranı \%50-90 arasında olduğu görülmüştür ve hastalığın en sık görülen bulgularından biridir. Çalışmamızda bu oran \% 42 olup literatür verilerine göre biraz daha düșüktür, bu durumun çalıșmanın retrospektif olmasından dolayı tüm hastaların göz bulgularına ulaşılamamış olması ile ilgili olabileceği düşünüldü (18).

Veriler retrospektif olarak toplanan çalışmamızda klinik değerlendirmede 113 hastanın aile öyküsüne ulașıldı. Bunlardan 71 (\%62.8) hastanın aile öyküsü pozitifti. 28 olguda anne ve/ veya akrabalarında, 38 olguda baba ve/veya akrabalarında, 5 olguda sadece kardeșlerinde NF1 tanısı mevcuttu. Bu bulgular literatür ile benzer niteliktedir $(16,19)$.

Yapılan çalışmalarda NF1'in erkeklerde daha sık olduğu belirtilmiştir (20). Bizim çalışmamızda da benzer şekilde NF1 erkeklerde daha sık izlenmiştir (\%55 erkek, \%45 kız).

NF1 hastalarda tanı kriterleri içerisinde yer almamakla birlikte beyin MRG incelemelerinde sıklıkla izlenen patoloji, T2 ve FLAIR ağırlıklı serilerde hiperintens olan, belli lokalizasyonlarda daha sıklikla saptanan (UBO) lezyonlardır. Bazen kistik dejenerasyon göstererek milimetrik kistik alanlar da bulundurabilirler. Bu lezyonlar yaş ilerledikçe gerileme eğilimindedir ve erişkinlerde karşımıza daha az çıkar (11).

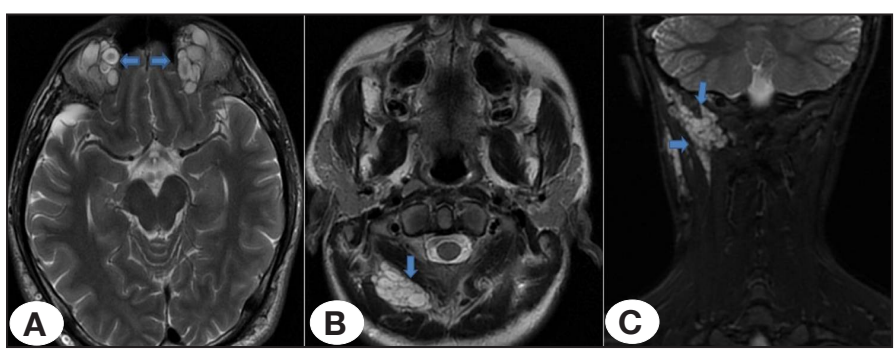

Resim 2: (A) Aksiyel T2A görüntü, orbita üst komșuluğunda bilateral santrali hipointens üzüm salkımı benzeri multinoduler (oklar). (B) sağ oksipital bölgede (ok) hiperintens multinoduler görünümde. (C) Koronal T2A görüntüde kas yapılar arasında geniş bir alana uzandığı izlenen (oklar) pleksiform nörofibrom ile uyumlu lezyonlar izleniyor.

Griffiths ve ark. (8) çalışmasında UBO'ların 4 yaşın altında daha az olduğu, 4-10 yaş arasında gelişerek maksimum sayı ve boyuta ulaştığı, 10 yaş üstünde ise boyut ve sayısında azalma izlendiğini bildirmişlerdir. Tariflenen bu lezyonlar glial proliferasyonda oluşan fokal bozukluk ya da yaş ilerledikçe kaybolan defektif miyelinizasyonlara bağı olabilir. Nedeni çok net bilinemeyen bu lezyonlar patolojik temellendirmeden kaçınmak için UNO/UBO (Unidentified Neurofibromatosis/Bright Object, Tanımlanamayan Nörofibromatöz/Parlak Cisim) ya da FASI (Fokal Artmış Sinyal Intensitesi) gibi isimlerle anılmışlardır. Benigndirler ve nörolojik bir sorun oluşturmazlar (21). Fakat kitle etkisi bulunan, görece büyük boyutlu, kontrastlanma gibi atipik özellikler gösteren ya da optik yollara yakın yerleșen hamartomatöz lezyonların takibinin ve optik gliomlardan ayıııı tanısının yapılması gerekmektedir (22).

Duffner ve ark. (23) NF1'li olgularda hamartomu \%62, hamartom dışı anormal bulguları \%12 bulmuşlardır. Biz de çalışmamızda beynin birçok bölgesinin bu lezyonlardan etkilendiğini gözlemledik. Bizim hastalarımızda \%79 (n:146) oranında intrakranial bir veya birden fazla sayıda UBO lezyonu izlenmiştir. Takiplerde hiç bir lezyonda büyüme olmamışıı. Bilateral globus pallidus tutulumu önceki yayınlarda da olduğu gibi en sık tutulum şekliydi $(8,24)$.

Intrakranial tümörler NF1 hastalarının yaklaşık \% 20 oranında görülür ve sporadik muadillerinden daha iyi prognoza sahiptir $(25,26)$. Gliomlar nörofibromatozis tip 1 hastalarında intrakranial kitleler içerisinde en yaygın görülen tümördürve nörofibromlardan sonra en sık görülen ikinci tümör tipidir. Gliomların çoğunluğu pilositik astrositomlardır ve bu tümörler genel olarak optik yolakta veya beyin sapında yerleşim gösterir (27). Bu lezyonlar nadiren malign karakter kazanıllar(18,28,29,30). NF1 ile ilişkili diğer beyin tümörleri ise medulloblastom ve malign schwannomadır $(31,32)$.

Histolojik olarak düşük dereceli astrositom olarak sınıflandırılan optik gliomlar NF1'li hastalarda en sık görülen intrakranial tümördür. Tüm optik trakt boyunca görülebilirler bazen optik sinirde veya kiazmada kontrastlanan kalınlaşma şeklinde izlenirler (2). 
Listernick ve ark. (33) yaptığı çalışmada en az bir tarafta optik sinir lezyonu görülme oranı \%15 bulmuşlardır. Yapılan diğer bir çalışmada bu oran \%22 olarak tespit edilmiştir (34). Bizim çalısmamızda \%13 hastada optik sinir lezyonu izlenmiştir. Çalışmamızda izlenen lezyonlar benzer şekilde T1 ağırlıklı görüntülerde izointens ya da hafif hipointens, T2 ağırlıklı görüntülerde hafif hiperintens olup değişken kontrastlanma özelliği göstermekteydi.

Araknoid kistler subaraknoid boşlukta yer alan ancak BOS ile ilişkisiz ince membrana sahip kistik lezyonlardır ve intrakranial yer kaplayan lezyonların \%1'ini oluştururlar (35). Genellikle konjenitaldirler, orta kranial fossada yerleşim gösterirler ve asemptomatiktirler ama baş ağrısı nöbet gibi nonspesifik semptomlara, kafa içi basınç artışı, hidrosefali, şift gibi ciddi tablolara da yol açabilirler (36).

Sánchez Marco ve ark. (37) yaptığı çalışmada 128 NF1 hastasında toplam 3 hastada araknoid kist tespit etmişlerdir. Bunun dışında NF1 ile araknoid kist birlikteliği literatürde vaka bildirimi şeklinde mevcuttur (38-40). Bizim çalısmamızda 9 (\%5) hastada araknoid kist izlenmiştir. Araknoid kistler NF1 hastalarda mevcut nörolojik tabloyu șiddetlendirebilirler. Genetik hastalıklarla birlikteliği bu ilişkide genetik faktörlerin de rol oynayabileceğini düşündürebilir.

Bazı çalışmalar NF1 olan çocuklarda hemisferik serebellar ve serebral gliom insidansında artış olduğunu göstermiştir (41). Serebellum ve beyin sapı genellikle insidental olarak saptanan bu lezyonların en sık lokalizasyonudur (42). Bizim hastalarımızdan 6 (\%3) tanesinde serebral parankim alanlarında patolojik korelasyonu yapılmış, 2 hastada da takipte stabil boyutlu ve radyolojik olarak öncelikle düşük gradeli glial tümör ile uyumlu olan lezyon izlenmiş̦tir.

Nörofibromlar NF1 hastalarda en sık görülen, periferik sinir kllıfı hücrelerinden kaynaklanan benign tümörlerdir. Periferik sinir sistemi boyunca görülebilirler. Ciltteki nörofibromlar tek bir periferik sinir, plexiform nörofibromlar ise bir fasikül demetinden veya daha büyük bir sinir pleksusundan ortaya çıkar. Periferik sinir kllıfı tümörleri NF1 hastalarında \% 20-50 oranında görülür ve hayat boyu \% 8-12 görülme riski vardır (4). Bizim çalışmamızda hastalarda retrospektif olarak taranan beyin MRG tetkiklerinde kesitler dahilinde baş-boyun bölgesinde 8 (\%4) hastada pleksiform nörofibrom, $9(\% 5)$ 'unda subkutan nörofibrom izlendi. Beyin MRG tetkiklerinde sadece kesitler dahilindeki lezyonlar incelendiği için oranlar literatüre göre düşük kalmıştır.

Hastaların \%90'ına daha ileri yaşlarda ortaya çıkabilen veya belirginleşebilen sütlü kahve lekelerinin, iris hamartomları veya nörofibromlar ile tanı konabilir, fakat 2 yaşından küçük hastalarda klinik bulgulara göre tanı koymak güçleşmektedir. NF1'li çocuklarda benign ve malign tümör gelişim sıklı̆ı da normal popülasyon ile karşılaştırılı̆ğında artış göstermektedir. Diğer nörokütanöz sendromlarda olduğu gibi bu hastalarda da kranium genel olarak morbidite ve mortalite üzerinde önemli etkisi olan tutulumların lokalizasyonudur. NF1' de nöro-radyolojik görüntüleme, klinik şüphe olan hastalarda ayıııcı tanı yapmak, tanısı olan hastalarda eşlik edebilecek patolojileri saptamak, hastalı̆ı̆ yaygınlığını ve komplikasyonları tespit-takip etmek için gerekli görülmektedir. Bu amaçla yüksek duyarllığı ve özgüllüğü nedeniyle beyin MRG tercih edilmektedir. Özellikle NF1 hastalarında gelişebilecek kraniyal tümörler açısından yaşamın ilk yıllarında yapıımış bir beyin MRG tetkiki karşılaştırma açısından değerlidir (16).

Sonuç olarak; araknoid kist-NF1 birlikteliği sanılandan daha sık olabilir ve hastanın morbitesini arttırabilir. Bu nedenle NF1 hastalarının takibinde araknoid kistler gözardı edilmemelidir. Çalışmamızda diğer klinik ve beyin MRG bulguları literatürdeki çalışmalar ile benzerlik göstermektedir. Hastaların erken yaşta tanı almaları, ailelerinin bilgilendirilmesi, genetik danışmanlık ve bu çocukların klinik takiplerinin farklı branş doktorlarından meydana gelen bir ekip tarafindan düzenli olarak yapılması hastalı̆ın mortalite ve morbiditesini en aza indirmek açısından önemli ve gereklidir. NF1'in radyolojik tanı ve takibinde kontrastlı beyin MRG tetkiki yeterli ve etkin bir yöntemdir.

\section{KAYNAKLAR}

1. Mentzel HJ, Seidel J, Fitzek C, Eichhorn A, Vogt S, Reichenbach J $\mathrm{R}$, et al. Pediatric brain MRI in neurofibromatosis type I. Eur Radiol 2005; 15:814-22.

2. Keleşoğlu KS, Keskin S, Sivri M, Erdoğan H, Nayman A, Koplay M. Genel Tıp Derg 2014;24:150-4.

3. Varan A, Sen H, Aydın B, Yalçın B, Kutluk T, Akyüz C. Neurofibromatosis type 1 and malignancy in childhood. Clin Genet 2016; 89: 341-45.

4. Evans DG, Howard E, GiblinC, Clancy T, Spencer H, Huson SM, et al. Birth incidence and prevalence of tumor-prone syndromes: estimates from a UK family genetic register service. Am J MedGenet A 2010;152A: 327-32.

5. Guillamo JS, Creange A, Kalifa C, Grill J, Rodriguez D, Doz F, et al. Prognosticfactors of CNS tumors in neurofibromatosis 1 (NF 1). A retrospective study of 104 patients. Brain 2003; 126:152-60.

6. Mukonoweshuro W, Griffiths PD, Blaser S. Neurofibromatosis type 1: the role of neuroradiology. Neuropediatrics 1999; 30:111-19.

7. Neurofibromatosis. Conference statement. Nationallnstitutes of HealthConsensus Development Conference. ArchNeurol 1988; 45:575-8.

8. Griffiths PD, Blaser S, Mukonoweshuro W, Armstrong D, MiloMason G, Cheung S. Neurofibromatosis bright objects in children with neurofibromatosis type 1: a proliferative potential ? Pediatrics 1999; 104: 49.

9. 9. Goldstein SM, Curless RG, Donovan Post MJ, R.M. Quencer A. A newsign of neurofibromatosis on magnetic resonance imaging of children. Arch Neurol 1989; 46: 1222- 4.

10. Balestri P, Calistri L, Vivarelli R, Bartalini G, Mancini L, Berardi $A$, et al. Central nervoussystemimaging in reevaluation of patientswithneurofibromatosistype 1. ChildsNervSyst 1993; 9: 448- 51

11. Özmen M. Nörokütan hastalıklar. İçinde: Neyzi O, Ertuğrul T (eds). Pediatri İstanbul: Nobel, 2002: 1368- 72. 
12. North K, Joy P, Yuille D, Cocks N, Mobbs E, Hutchins P, et al. Spesificlearningdisability in childrenwithneurofibromatosistype 1: significance of MRI abnormalities. Neurology 1994; 44: 878- 83.

13. JoyP,Roberts C, NorthK, DeSilvaM. Neuropsychologicalfunctionand MRI abnormalities in neurofibromatosis type 1. Dev Med Child Neurol 1995; 37: 906- 14.

14. Ozonoff S. Cognitiveimpairment in neurofibromatosistype 1. Am J Genet 1999; 89: 45- 52.

15. Plon SE, Malkin D. Childhood cancer and heredity. In: Pizzo PA, Poplack DG, editors. Principles and practice of pediatric oncology, 5 ed. Lippincott-Roven, Philadelphia 2006: 14- 37.

16. SaltıkS, Dönmezer B, YükselE, Çakı S, Ergüven M. Nörofibromatozis tip 1 hastalarında klinik ve kraniyal manyetik rezonans görüntüleme Özellikleri. Türk Pediatri Arşivi 2005; 40: 94- 101.

17. Fluksová D. Neurofibromatóza typu 1, Pardubice, Çek Cumhuriyeti, University of Pardubice Faculty of Chemical Technology. 2018.

18. Kinori M, Hodgson N, Zeid JL. Ophthalmic manifestations in neurofibromatosis type 1. Surv Ophthalmol 2018;63:18-33.

19. Hirbe AC, Gutmann, DH. Neurofibromatosis type 1: a multidisciplinary approach to care. Lancet Neurol 2014;13:834-43.

20. Gutmann DH. Recentin sight into neurofibromatosis type 1: clear genetic progress. Arch Neurol 1998; 55:778-80.

21. Kresak JL, Walsh M. Neurofibromatosis: A Review of NF1, NF2, and Schwannomatosis. J Pediatr Genet 2016; 5:98-104.

22. Elster AD. Radiologic screening in neurocutaneous syndromes: strategies and controversies. AJNR Am J Neuroradiol 1992;13:1078-82.

23. Duffner PK, Cohen ME, Seidel FG, Shucard DW. The significance of MRI abnormalities in children with neurofibromatosis. Neurology 1989;39:373-78.

24. Khan A, Beri S, Baheerathan A, Balki A, Hussain N, Gosalakkal J. Globus pallidus high-signal lesions: A predominant MRI finding in children with neurofibromatosis type. Ann Indian Acad Neurol 2013;1:53-56.

25. Rosser PRT. Intracranial neoplasms in children with neurofibromatosis 1. J Child Neurol 2002;17:630-37.

26. Jett K, Friedman JM. Clinical and genetic aspects of neurofibromatosis 1. Genet Med 2010; 12: 1-11.

27. Yohay K. Neurofibromatosis type 1 and associated malignancies. Curr Neurol Neurosci Rep 2009; 9:247-53.

28. 28. Roach ES. Neurocutaneous syndromes. Pediatr Clin North Am 1992; 39: 91-20.

29. 29. Lewis RA, Gerson LP, Axelson KA, Riccardi VM, Whitford RP. Von Recklinghausen neurofibromatosis. II: Incidence of optic gliyoma. Ophthalmology 1984; 91: 929- 36.
30. Kornreich L, Blaser S, Schwarz M, Shuper A, Vishne TH, Cohen $\mathrm{IJ}$, et al. Optic pathway gliyoma: correlation of imaging findings with the presence of neurofibromatosis. R Am $J$ Neuroradiol 2001;22:1963- 9.

31. Korf BR. Malignancy in neurofibromatosis type 1. Oncologist 2000;5:477-85.

32. Cohen BH, Kaplan AM, Packer RJ. Management of intracranialneoplasms in children with neurofibromatosis type 1 and 2. The Children's Cancer Study Group. Pediatr Neurosurg 1990-1991:16: 66-72.

33. Listernick R, Charrow J, Greenwald MJ, Esterly NB. Optic gliomas in children with neurofibromatosis type 1. J Pediatr 1989;114:78892.

34. 34. Van Es S, North KN, McHugh K, De Silva M. MRI findings in children with neurofibromatosis type 1: a prospective study. Pediatr Radiol 1996;26:478-87.

35. Menkes JH. Arachnoidal Cysts in Sarnat HB, Menkes HJ, editors. Child Neurology. 6th. ed. Lippincott Williams andWilkins, Philadelphia, 2000:377-37.

36. Atalar, M , Karakuş, K, Yıldız, B , Şalk, I. Location, sidedness, and sex distribution of incidental intracranial arachnoid cysts in childhood: An MRI study. Cumhuriyet Medical Journal 2018;40: 25-33.

37. 37. Sanchez-Marco SB, Lopez-Pison J, Serrano-Vinuales I, TroyasFernandez de Garayalde L, Lafuente-Hidalgo M, Monge-Galindo L. Neurofi bromatosis type 1 and att ention-defi cit disorder. Our current experience. Rev Neurol 2019;68:7-10.

38. Martinez-Lage JF, Poza M, Rodriguez Costa T. Bilateral temporal arachnoid cysts in neurofibromatosis. J Child Neurol 1993;8:38385.

39. Cho SB, Kim HS, Yang, MS, Cho KW. Type 1 neurofibromatosis associated with asymptomatic cystic malformations of central nervous system (CNS). Int J Dermatol 2009; 48:330-2.

40. 4Wegener M, Prause JU, Thygesen J, Milea D. Arachnoid cyst causing an optic neuropathy in neurofibromatosis 1. Acta Ophthalmol 2010;88:497-9.

41. Riffaud L, Vinchon M, Ragragui O, Delestret I, Ruchoux MM, DhellemmesP Hemispheric cerebral gliomasin children with NF 1: arguments for along-term follow-up. Childs Nerv Syst 2002;18:437.

42. Pollack IF, Shultz B, Mulvihill JJ. The management of brainstemgliomas in patients with neurofibromatosis 1. Neurology 1996;46:1652-60. 